\title{
A literatura infantil na alfabetização: a formação da criança leitora
}

\author{
Lilane Maria de Moura Chagas* \\ Chirley Domingues**
}

\section{Resumo}

O presente texto aborda algumas formas de se pensar a literatura infantil no ciclo de alfabetização do Ensino Fundamental. Tem-se, ainda, a pretensão de apresentar algumas possíveis formas de aproximação da literatura nesse nível de ensino. Acreditase que, ao integrar ativamente a literatura infantil no processo da alfabetização (conhecimentos da oralidade e da escrita, das diversas formas verbais e não verbais de se compreender e descobrir o mundo) e na aquisição e ampliação da linguagem, estaremos contribuindo para a formação literária das crianças. Assim, em um primeiro momento, e sem esgotar o tema, desenvolvem-se algumas questóes teóricas em relação à literatura Infantil, à leitura e à criança. No segundo momento, são tecidas algumas reflexóes sobre as práticas de leitura que as crianças do ciclo de alfabetização estáo vivenciando a partir do contato com o Acervo Complementar do Programa Nacional do Livro Didático (PNLD) e do Programa Nacional de Bibliotecas Escolares (PNBE) incluídos no material distribuído pelo Programa Nacional de Alfabetização na Idade Certa (PNAIC) no Brasil. Ressalta-se uma antiga e permanente preocupação quando se trata da relação literatura e educação no que diz respeito a como tem sido trabalhada a literatura produzida para as crianças. Dessa forma, que implicaçóes têm a literatura inserida nos programas de formação de professor? Finaliza-se o texto dando destaque para os programas de incentivo à leitura como uma contribuição significativa para a formação da criança leitora.

Palavras-chave: Literatura Infantil. Formação do leitor. Ciclo de alfabetização.

\footnotetext{
* Doutora em Educação pela Universidade de São Paulo (USP). Professora do Curso de Pedagogia da Universidade Federal de Santa Catarina (UFSC).

** Mestre em Literatura e Doutoranda em Educação na Universidade Federal de Santa Catarina (UFSC). Professora do Curso de Letras da Universidade do Sul de Santa Catarina (UNISUL).
} 


\section{Introdução}

O presente texto aborda algumas formas de se pensar e de aproximar a literatura infantil no ciclo de alfabetização ${ }^{1}$ do Ensino Fundamental, a partir de estudos realizados em pesquisa de doutorado e de pesquisas em andamento do Núcleo de Estudos e Pesquisas em Alfabetização e Ensino de Língua Portuguesa (Nepalp), da Universidade Federal de Santa Catarina (UFSC).

No item que segue, teceremos algumas aproximaçóes conceituais para se pensar a Literatura Infantil no Ciclo de Alfabetização. No segundo momento, objetivamos pensar mais especificamente sobre as relaçóes entre literatura infantil e o trabalho desenvolvido com os acervos que chegam às escolas, resultado de políticas públicas de incentivo à leitura como, por exemplo, o acervo distribuído pelo Programa Nacional de Bibliotecas Escolares (PNBE) ${ }^{2}$ e pelo Programa de Formação Continuada dos professores pelo Pacto Nacional de Alfabetização na Idade Certa (PNAIC).

Salientamos que o acervo distribuído para o PNAIC vem como uma complementação dos programas anteriores e ambos são políticas públicas que vêm a somar às demais políticas em vigência no país para a efetiva formação da criança leitora.

Ao pensarmos especificamente sobre as relaçóes entre literatura infantil e trabalho pedagógico nos remete à antigas e permanentes preocupaçóes: como tem sido trabalhada a literatura produzida para as crianças? Que implicaçóes se têm hoje inseridas nos programas de formação de professor? Até que ponto a visão do uso utilitário tem sido superada nas práticas de leitura da literatura infantil? Que postura docente tem sido produzida no intuito de valorizar o livro de literatura como produção cultural para as crianças sem "didatizá-la"?3 Náo objetivamos responder a todas essas questóes neste texto, no entanto, tais questóes, no nosso entendimento, nos colocam em estado de alerta quando nos deparamos com o trabalho desenvolvido, no caso brasileiro, com os acervos que chegam às escolas, resultados de tantas políticas públicas de incentivo à leitura como, por exemplo, o acervo distribuído pelo PNBE e pelo PNAIC. Esse último nos leva, ainda, a outra preocupação que versa sobre a formação continuada dos professores receptores desse acervo, que são os professores alfabetizadores. Sendo assim, no presente artigo teceremos algumas reflexóes acerca da formação literária na escola e a Literatura Infantil no ciclo de alfabetização a partir do PNAIC. 


\section{Algumas aproximações conceituais: a formação literária na escola}

A formação literária no ciclo de alfabetização é uma tarefa muito importante para os professores que atuam no Ensino Fundamental (nos três primeiros anos de escolarização).

Sabemos que no convívio com os livros as crianças aprendem sobre si, sobre os outros e sobre o mundo. Mas, é importante destacar que nesse encontro com os livros elas necessitam da mediaçáo do adulto. Nesse caso, em se tratando de ciclo de alfabetizaçáo, é preciso, então, a mediação do professor alfabetizador.

Dessa forma, cabe a esse professor criar situaçóes de ensino que possam propiciar à criança o acesso ao texto literário e o encontro dela com os diversos gêneros como poemas, contos, fábulas, entre outros, e com os livros e ou demais instrumentos e suportes de leitura que desafiem e favoreçam os saltos qualitativos para o desenvolvimento das crianças e sua familiarização no processo de alfabetizaçáo e com a cultura escrita.

$\mathrm{Na}$ tarefa de inserir a criança na cultura escrita, além da apropriação do Sistema de Escrita Alfabética (SEA), cabe ensinar a função social da escrita, seu sentido e significado na cultura letrada. Consta no documento da Secretaria de Educação Básica (SEB) que a escola precisa ser:

[...] um ambiente que permita a ampliação das possibilidades de conhecimento das crianças em situaçóes cuidadosamente planejadas, que favoreçam o uso da língua em diferentes situaçóes ou contextos sociais, valorizando sua função diversificada e sua variedade de modos de falar. Para isso, a realização de um trabalho criativo e prazeroso que possibilite o desenvolvimento de habilidades comunicativas nos primeiros anos do Ensino Fundamental, por meio de diversas situaçóes orais e escritas, deve ser uma preocupação constante do professor. (BRASIL, 2012a, p. 19).

Ressalta-se aqui, além da função social anteriormente destacada, o papel da escola que favorece o acesso das crianças ao mundo letrado sistematizado, possibilitando o convívio com material escrito em suas várias formas e gêneros e seus diversos usos nas interaçóes sociais. Claro que, com esta afirmação, 
não se elimina o conhecimento de que as crianças, desde que nascem, estão rodeadas e inseridas no mundo da escrita, de signos, sentidos e significados. A inserção na escola é mais um espaço, um lugar, uma etapa em que outras especificidades e possibilidades das relações sociais estão postas em movimento para o desenvolvimento das crianças.

A leitura como uma prática social e, especificamente, as atividades com a literatura infantil para o processo de letramento na escola e para a formação da criança leitora são fundamentais no ciclo de alfabetização. As brincadeiras com parlendas, rimas e poemas possibilitam o trabalho no processo de alfabetização na dimensão lúdica, levando as crianças a prestarem atenção no som, no ritmo das palavras e, consequentemente, vai também se desenvolvendo a dimensão estética e poética.

Sendo assim, o ensino da linguagem escrita de forma sistematizada e sequenciada na sala de aula possibilita diversas alternativas com o trabalho com as narrativas literárias. E esse trabalho requer uma compreensão pelo professor de sua importância e função, já que ler e narrar histórias são atividades que possibilitam aos seus ouvintes ou leitores tornar a história viva e atualizada, seja esse leitor adulto ou criança, professor ou estudante. Segundo Machado (2004, p. 23), a leitura ou narraçáo de um conto possibilita:

[...] uma experiência singular, única, que particulariza para cada um de nós, no instante da narraçáo, uma construção imaginativa que se organiza fora do tempo da história cotidiana, no tempo do "era". Tal experiência diz respeito à universalidade do ser humano e, ao mesmo tempo, à existência pessoal como parte dessa universalidade. Pois, se náo fosse assim, como seria possível que compreendêssemos uma história de cinco mil anos, como a Epopéia de Gilgamesh ou a versão da Cinderela dos índios algonquinos da América do Norte? Por que essas histórias falam para nós, fazem sentidos, independentemente de conhecermos qualquer coisa que seja sobre a Suméria de quatro mil anos atrás, ou uma cultura indígena americana? À medida que ouvimos a história, somos transportados para "lá", esse local desconhecido que se torna imediatamente familiar. A história só existe quando é contada ou lida e se atualiza para cada ouvinte ou cada leitor [...]. 
Nas palavras da autora, verificamos ser muito importante para o desenvolvimento humano a experiência de ouvir, relatar e ler um conto como experiências singulares que se manifestam nessa relação. Passagens, emoçóes dos personagens, cenários, aventuras, desenrolar e desfechos da trama são ressaltados em diferentes sentidos compartilhados e momentos históricos. E essa é a riqueza da narrativa literária - provocar sentidos e significados universais, particulares e singulares, que fazem parte da existência humana e favorecem a própria compreensáo da existência singular de cada sujeito, ao desenvolvimento de sua subjetividade em processo de objetivação com o mundo real. Ademais, ainda de acordo com a autora:

[...] O que importa é que o conto estabelece uma conversa entre sua forma objetiva - a narrativa - e as ressonâncias subjetivas que desencadeia, produzindo um determinado efeito particular sobre cada ouvinte. As imagens do conto acordam, revelam, alimentam e instigam o universo de imagens internas que, ao longo de sua história, dão forma e sentido às experiências de uma pessoa no mundo. (MACHADO, 2004, p. 23-24).

Entendemos, segundo as palavras da Machado (2004), que as narrativas tradicionais são verdadeiras obras de arte de tempos imemoriais, transmitidas oralmente e posteriormente por escrito, ao longo dos séculos, pelas diferentes culturas e transmitidas de geração para geração. As narrativas viajavam na memória e na melodia da voz particular de cada narrador, e esta constatação nos permite defender que as escolas (e também outros ambientes, como as bibliotecas, as salas de leituras, as salas de cinema) sejam um espaço para que a criança tenha acesso a histórias clássicas, tradicionais de diferentes culturas.

Sabemos que o trabalho com a narrativa literária requer um aprendizado diferenciado, um tempo mais extenso, um trabalho mais consciente com a palavra. Um tempo para a produção de imagens enquanto a narrativa é lida ou narrada, tanto por quem escuta como por quem narra. E, na contemporaneidade, é a escola um desses lugares para realizar essa ação e possibilitar às crianças essa experiência significativa com as histórias, os poemas e as cançóes. Um dia na vida de uma sala de aula, destaca Paley (1998, p. 142, tradução nossa), "é uma trama em que muitos fios se entrelaçam e uma aprendizagem compartilhada se produz". 
Consequentemente, produz-se também na criança a necessidade humanizadora de tornar-se leitora, sobretudo se considerarmos que ler é:

[...] reunir experiências de outras leituras e vivências para atribuir significados e sentidos a um texto. Quando somos capazes de estabelecer relaçóes entre o texto que temos à frente dos olhos e as nossas experiências anteriores, é possível afirmar que existe compreensão. Ler é, portanto, compreender. (BISSOLI; CHAGAS, 2012, p. 65).

Essa concepção supera aquela que apresenta a leitura como decifração de palavras. Uma vez que a prática de leitura como compreensão possibilita reunir conhecimentos e emoção no diálogo entre o leitor e o material lido na ação efetiva de se apropriar das palavras por aquele que lê, do significado delas, dos múltiplos sentidos, e não apenas das letras, especialmente, na prática da leitura literária. Bissoli e Chagas (2012, p. 66-67) salientam que :

[...] A leitura possibilita inúmeras escolhas: do tipo de texto a ser lido, da finalidade da tarefa de leitura, dos sentidos atribuídos ao texto. Ler é, sobretudo, uma escolha: de o que ler; do ler; do quando ler; de não ler. Mas, para que possa configurar-se como opçáo, deve ser uma capacidade de todas as pessoas, indiscriminadamente. Ler também pode ser espiar. Metaforicamente, quando lê, o leitor espia. Pela janela dos significados dos textos, o leitor espia o pensamento do outro, os fatos, o conhecimento historicamente acumulado. E, nesse processo, torna seus os objetos da reflexão e da escrita de outrem. Ao ler, o leitor fluente também é um espião: segundo Smith (1999), ao tomar contato com o texto, todo leitor "espia" seu conteúdo e, a partir disso, faz previsóes de sentido essenciais para a sua compreensão. Ao buscar marcas textuais, ao correr os olhos sobre um índice, ao perceber figuras e símbolos, o leitor "espia” o texto e, como espião, formula hipóteses que vão atuar, progressivamente, na construção dos significados, na apreensão das ideias e na sua transmutação em pensamento. [...] Ler é, assim, construir o pensamento através da apropriação das palavras do outro, da atribuição de sentidos aos 
significados partilhados socialmente. Ler é uma atividade que culmina, portanto, na elaboração da consciência humana.

O sentido e o significado da leitura e da formação leitora culminam, ainda, com a dimensão coletiva que se constitui no ato de ler. Nessa produção humana, os que não sabem ler aprendem com os que sabem e, no processo de ensinar e aprender, são compartilhados significados de mundo, emoçóes, conhecimento (MANGUEL, 1997; FOUCAMBERT. 1997; SMITH, 1999). Os professores alfabetizadores possuem uma função fundamental nessa ação efetiva de tornar as crianças leitoras. E, nesse sentido,

[...] a literatura infantil constitui elemento humanizador. Por lidar com a linguagem de forma sensível às emoçóes humanas, ela possui um caráter educativo: educa à medida que amplia as referências — ou leituras de mundo (Freire, 1997) — do leitor, possibilitando a apropriaçáo de saberes sobre a linguagem, sobre a expressividade, sobre os valores, sobre a cultura humana. Possui especificidades. Constitui um objeto cultural com destinação social própria, como ademais, todas as literaturas: conclamar a beleza, as emoçóes, a expressividade, a palavra como manifestação de humanidade que evoca a humanizaçáo do leitor. Como possibilidade de atribuição de sentidos por aquele que lê, oportuniza a produção de novas maneiras de expressar sua individualidade, sua identidade. (BISSOLI; CHAGAS, 2012, p. 111).

Cabe, então, desenvolver um trabalho com a literatura que provoque a imaginação das crianças, o exercício da sensibilidade para surgir a própria voz dela no encontro com o texto literário. A dimensão artística constitutiva da literatura provoca o desenvolvimento da sensibilidade, de experiências emocionais e de expressão diversa que precisam ser vivenciadas como parte da formação humana. Dessa forma, segundo Bissoli e Chagas (2012, p. 122),

[...] para superar essa realidade, é preciso que a escola - como espaço comum para a maioria das crianças, hoje - propicie momentos voltados para o lúdico, para a imaginaçáo, para as atividades coletivas de 
discussão, de criação. É preciso que a própria formação dos professores (inicial e continuada) promova a reflexão sobre a importância desses momentos para o desenvolvimento das crianças, mudando o ponto de vista sobre o que seja educar. Não se trata de abolir os conteúdos de ensino, mas de torná-los significativos em suas próprias peculiaridades, despertando a curiosidade dos alunos para a sua aprendizagem, sem usar a Arte e o jogo como pretextos, mas como oportunidades de ampliar as experiências da criança, de contribuir para um desenvolvimento mais abrangente. E a literatura pode ser uma âncora para esse tempo de fruição, que educa sem pedagogizar.

Considerando as discussóes acima, que tematizam a formação do professor e o lugar que a literatura infantil ocupa hoje nas salas de aula do Ensino Fundamental no Brasil, interessa-nos realizar uma reflexão sobre o PNAIC, um Programa de formação de professores alfabetizadores que promove a leitura e o uso de livros literários e didáticos para as crianças que iniciam o processo de alfabetização nas escolas do nosso país. Nosso objetivo, neste texto, é discutir o referido Programa, dando ênfase à experiência outorgada na formação dos professores do estado de Santa Catarina, uma vez que este é o estado no qual atuamos como supervisoras do PNAIC e sobre o qual temos algumas contribuiçôes em relação à temática da literatura infantil em salas de aula de alfabetização, aspecto que desenvolveremos a seguir.

\section{A Literatura Infantil no ciclo de alfabetização: algumas reflexões a partir do PNAIC}

O PNAIC é um compromisso do governo federal, em parceria com os governos estaduais e municipais, e tem como meta a alfabetizaçáo de todas as crianças brasileiras ao final do terceiro ano do Ensino Fundamental. Trata-se de um conjunto de programas, materiais e referências curriculares e pedagógicas, que contribuem para a alfabetização e o letramento das crianças matriculadas nas escolas públicas do primeiro ao terceiro ano do Ensino Fundamental.

A partir das experiências do PNAIC em Santa Catarina, de 2013 a 2014, foi realizada uma pesquisa, na qual um dos objetivos foi conhecer e evidenciar 
as experiências significativas que as crianças têm quando entram em contato com o Acervo Complementar - livros distribuídos pelo referido Programa ${ }^{4}$. Nas observaçóes efetivadas, notamos que as atividades de aproximação da criança com livro, além de possibilitar o contato dela com um rico acervo, que conta com mais de 100 livros de literatura infantil ${ }^{5}$, vai além e a leva ao mundo da ficção, ao contato com um universo imaginário e com uma gama de possibilidades de gêneros literários como a poesia, a prosa e o teatro.

$\mathrm{O}$ acesso a esse material ainda é considerado insuficiente e não sistemático, não obstante o envio de obras literárias para as escolas públicas brasileiras por alguns governos de décadas anteriores objetivando a circulação e uso de livros da literatura ${ }^{6}$. Alguns livros que chegavam às escolas eram acervos destinados às bibliotecas ou aos espaços alternativos das escolas que porventura não possuíam bibliotecas. Contraditoriamente, sabe-se que, apesar dessa política, muitas escolas deixavam os livros armazenados em caixas ou em estantes, dificultando o acesso das crianças ao livro.

É necessário deixar registrado que o Acervo Complementar, bem como todo o material distribuído pelo PNAIC, além das questóes que merecem destaque, como a qualidade editorial dos livros, consideramos fundamental, ainda na distribuição desse material, o fato dele vir, no movimento da formação continuada dos professores alfabetizadores, com uma explícita indicação nos Cadernos de Formação - "para uso coletivo em sala de aula", questão que indica uma definição importante sobre o lugar onde os livros devem permanecer para as possibilidades reais de seu uso. Nessa direção, há também indicaçóes para que as crianças tenham, de fato, acesso às obras, ou seja, a criação do espaço para a garantia efetiva de prática de leitura a ser organizado em todas as salas do primeiro ao terceiro ano do Ensino Fundamental.

Contudo, apesar dessas indicaçôes, é importante considerar o que a pesquisa revelou, no que tange alguns obstáculos, que os professores e a escola, como um todo, lidam para manter a acessibilidade e a atratividade desses espaços organizados no interior da sala de aula. A realidade das escolas brasileiras, no entanto, nem sempre possuem espaços físicos adequados e materialidade de suportes e estantes para disposiçáo das obras. Outro obstáculo apontado, é que as salas de alfabetização geralmente dividem o mesmo ambiente com outras turmas de outros turnos.

Sendo assim, e considerando tais aspectos, bem como o intuito de aproximar as crianças da literatura, podemos afirmar, a partir dos relatos dos 
professores envolvidos com o Pacto em Santa Catarina, que foram realizadas açóes que revelaram a relação da criança com o livro, ultrapassando o espaço da escola e envolvendo as famílias nas práticas efetivas de leitura de textos literários. Isso se dá porque os livros são levados para casa e lidos por essas crianças, por seus pais, irmãos e avós, o que demonstra a reverberação que as obras literárias distribuídas pelo programa têm gerado, seja com as leituras compartilhadas, ou em outras atividades com os livros, como a contação de histórias e, até mesmo, o simples manuseio das obras, efetivando assim a interaçáo dos leitores com os livros.

Ao depararmos com propostas como as do Programa Nacional do Livro Didático (PNLD) e do Programa Nacional de Bibliotecas Escolares (PNBE), que, desde 2010, mais do que a distribuiçáo de livros didáticos, incluem um Acervo Complementar (livros literários), percebemos que houve um avanço em relação à literatura no ciclo de alfabetização, configurando-se como apoio significativo para ampliar o repertório literário das crianças, além de oferecer suporte pedagógico aos professores e atraí-los para a literatura, possibilitandolhes o prazer da fruição estética e poética que muitas vezes estão ausentes nos textos literários que circulam em outros suportes, como o próprio livro didático com o qual o professor tem mais contato, sobretudo nas escolas de ensino fundamental.

No caso do PNAIC, a proposta para os professores trabalharem com o Acervo Complementar - livros literários - é planejar, na organização do trabalho pedagógico, uma leitura permanente, cujo objetivo seja o desenvolvimento da fruição. Durante os cursos de formação, os professores realizavam, sistematicamente, Leitura Deleite ou de Fruição (BAZZO; CHAGAS, 2014). Essa prática de leitura faz parte da atividade formativa dos professores e tem uma seção própria em todos os Cadernos $^{7}$ de formação do Pacto. No Caderno de Apresentação, a Leitura Deleite vem como um tópico importante, a saber:

Essa estratégia é muito importante nos processos de formação de professores alfabetizadores, pois favorece o contato do professor com textos literários diversos. $\mathrm{O}$ momento da leitura deleite é sempre de prazer e reflexão sobre o que é lido, sem se preocupar com a questão formal da leitura. É ler para se divertir, sentir prazer, para refletir sobre a vida. Tal prática, no entanto, não exclui as situaçôes em que se conversa sobre os textos, pois esse 
momento também é de prazer, além de ser de ampliação de saberes. (BRASIL, 2012c, p. 29).

Na citação acima, embora haja uma indicação da leitura prazerosa, importa destacar que, conforme pontuado por Bazzo e Chagas (2014), a leitura deleite pressupóe uma elaboração mediada em pares e exige trabalho, além de promover uma mudança de percepção de mundo e de agir sobre ele.

Além da preocupação com a leitura dos professores, havia, ainda, outra indicação que merece destaque quando estamos tratando da formação docente no PNAIC. Estamos nos referindo a um dos objetivos que enfatiza que se torna indispensável ao professor alfabetizador "Compreender a importância da literatura nos anos iniciais do Ensino Fundamental e planejar situaçóes de uso de obras literárias em sala de aula" (BRASIL, 2012b, p. 31). Eis aqui um ponto significativamente relevante que diferencia esse acervo, ou seja, ele deve estar ao alcance das crianças em sala de aula e disponível para que elas tenham contato com esse material, possibilitando, assim, uma relação de continuidade, uma vez que, agora, os livros de literatura passam a fazer parte do cotidiano da sala de aula e os professores podem ampliar significativamente suas possibilidades de ações diárias.

Diante do exposto, percebemos o quanto era importante na formação do professor esse aspecto, sobretudo considerando a realidade dos que participavam do PNAIC, ou seja, professores alfabetizadores. Dessa forma, durante o nosso trabalho na formação dos professores, nos deparamos com as seguintes indagaçóes:

- Como capacitar esses professores, que estão em contato com crianças ainda em processo de alfabetização, para o trabalho com a leitura literária, considerando os objetivos do Pacto, sem descaracterizar a literatura, mas, pelo contrário, potencializando a sua função estética?

- Como auxiliar os professores, ou como orientá-los, para o desenvolvimento de atividades significativas com a literatura infantil para crianças que ainda não dominavam o sistema de escrita?

Essas interrogaçóes complementam o avanço indicado, qual seja, o material ao qual nós e os professores tínhamos acesso, a oportunidade de inúmeras trocas das diversas experiências desenvolvidas pelos professores partícipes do PNAIC e o acervo literário que estava a nossa disposição. Isso possibilitou um fecundo intercâmbio com os professores em relação à literatura para as crianças 
rompendo, assim, o "círculo de reprodução ou da permissividade, permitindo que a leitura literária seja exercida sem o abandono do prazer" (COSSON, 2009 , p. 23), e envolvendo as crianças, mesmo aquelas que não tinham um domínio depurado da leitura, em uma experiência de leitura compartilhada.

Já no início do nosso contato com os professores, chamou-nos a atenção o zelo deles com material. E, nessa direção, é importante destacar que para uso em sala de aula foram organizados os espaços da leitura objetivando tornar a leitura do livro literário mais prazerosa. Para tal, foram confeccionados tapetes, colchas e almofadas, varal com os livros, cestas literárias, malas de livros e baús de leituras, tornando o espaço mais aconchegante para o leitor e atraente para a leitura. Para que as crianças pudessem levar os livros para a casa, foram confeccionadas sacolas, pastas e bolsas personalizadas, evidenciando a preocupação do professor com a leitura, garantindo, ainda, a socialização e a circulação dos livros literários fora do espaço restrito da escola. Essas açóes realizadas pelos professores nos fizeram perceber que estes haviam incorporado a posse do material, revelando uma relação de reciprocidade com a literatura além de criarem possibilidades de açóes e dinâmicas de leitura, como: narração de histórias; leitura individualizada e leitura orientada na biblioteca, leitura ao ar livre e leitura de recreio. Além da apropriação de alguns critérios importantes na escolha e seleção dos livros, como, por exemplo, a qualidade do texto e o projeto gráfico que estão diretamente relacionados ao trabalho estético com a linguagem.

A pesquisa nos permitiu constatar que é possível uma mudança de prática com a leitura dos livros literários no Ciclo de Alfabetização. Para ilustrar nossa constatação, recorremos ao depoimento de uma professora partícipe do PNAIC em um dos encontros de formação. A professora enfatizou que o pacto fortaleceu a formação literária não somente das crianças, mas também do próprio professor alfabetizador quando mostrou como usar a literatura na alfabetização, além de oferecer recurso e possibilitar o acesso às obras. Essa compreensão, a partir das atividades propostas para o trabalho com a literatura, segundo a docente, ampliou também a sua compreensão do ensino. Isso se manifesta, sobretudo, quando essa professora assinalou que "não podemos só oferecer instrumentos, temos que ensinar e aprender como utilizá-los”. O processo de conhecimento na formação se estende na manifestação didática na sala de aula.

Vários relatos das professoras destacam que o Acervo literário movimentou novas atividades na escola, ultrapassando os limites desse espaço. Destacaram os 
momentos de leitura da família com as crianças em casa com os avós, com os irmãos mais velhos e mais novos, e até com os vizinhos. Também, leitura com os pais e as crianças antes das reunióes para a entrega dos boletins, ou quando os pais estão aguardavam para serem atendidos pela direção ou pela coordenação pedagógica da escola, entre outras açóes e movimentos.

Como podemos ver, o Acervo Complementar tornou-se uma interessante ferramenta para a formação leitora da criança de textos literários, principalmente para as crianças de classe social menos favorecida, que, em ampla maioria, não têm a oportunidade de ter contato com o repertório da Literatura Infantil fora da escola.

Podemos afirmar também que esse material pode ser visto como um instrumento de inclusão, pois é inegável que para muitas crianças das escolas públicas brasileiras seria bastante difícil o acesso a materiais de qualidade. A amplitude que o referido acervo tem alcançado evidencia, ainda, que a participação ampla e comprometida do professor, ao explorar essas obras e criar possibilidades de leituras diversas, dentro e fora das escolas, é o caminho para que todas as nossas crianças possam vivenciar o encontro com a leitura literária com a qualidade que almejamos ver expostas em todos os índices de avaliação da educação brasileira.

\section{Palavras finais}

Destacamos no início do texto que a função social da escola possibilita a inserção das crianças ao mundo letrado, possibilitando o convívio com material escrito em suas várias formas e gêneros e seus diversos usos nas interações sociais.

Podemos destacar que a inserção de Acervos dos Programas PNLD Alfabetização na Idade Certa e do PNBE nos cursos de Formação Continuada para os professores alfabetizadores e as disciplinas de Literatura Infantil nos currículos dos Cursos de Formação de Professores já sinalizam práticas diferenciadas de professores alfabetizadores nas escolas públicas que em suas atividades com as narrativas literárias capturam e envolvem as crianças na leitura, criam estratégias para dispor o acervo, realizam diferentes estratégias de mediação de leitura na sala de aula, buscam alternativas de visibilidade às obras de literatura no intuito de formar a criança leitora de textos literários no cotidiano escolar. Não obstante, é necessário continuar realizando um amplo investimento por parte do Estado na educação em geral e especificamente na formação de 
professores com projetos, como de formação de leitor, principalmente nas escolas. A frequência de projetos coletivos de leitura possibilita troca de ideias entre os colegas sobre livros de qualidade, experiência de leitura, troca de sites na internet sobre narrativas literárias, o contato direto das crianças com as obras, experiências vividas pelas crianças, entre outras possibilidades.

Acreditamos e defendemos a leitura, o contato com os livros, com as histórias, com a poesia como uma possibilidade de humanizar-se, apropriandose dos conhecimentos socialmente produzidos. Formar crianças leitoras com consciência desse processo e com atuação autônoma e fluente sobre a leitura reconhecendo suas necessidades é tarefa da escola. E cabe aos professores desenvolver cada vez mais reflexóes, projetos e práticas de leitura para formar efetivamente leitores. Para tal fim, é mister compreender a infância como uma categoria histórica e produzida socialmente, entender a infância na contemporaneidade, as contradiçóes que as relaçóes sociais apresentam, e, nesse movimento contraditório, criar espaços para o uso da literatura, entre outras dimensôes estéticas, como uma forma humanizadora e de superação de práticas alienantes. Acreditamos em práticas voltadas para a criação de novas necessidades universalizadoras e libertadoras que possibilitem a formação do ser humano em suas máximas capacidades.

Sem dúvida que pensar a educação e a literatura é pensar a formação de sujeitos históricos capazes de atuar para a transformação, pelo direito e democratização à leitura, à literatura e a todo conhecimento produzido pela humanidade. Os professores alfabetizadores têm essa intencionalidade posta na sua ação e nos objetivos políticos e filosóficos da educação. Assim desejamos.

\section{Notas}

${ }^{1}$ Cf. Resolução n. 7, de 14 de dezembro de 2010, que estipula o tempo escolar em três anos ( $1^{\circ}$. ao $3^{\circ}$ ano) em ciclo sequencial denominado de "anos da alfabetização" (BRASIL, 2010).

${ }^{2}$ O Programa Nacional Biblioteca da Escola (PNBE) "é um Programa que promove 'o acesso à cultura e o incentivo à leitura nos alunos e professores por meio da distribuição de acervos de obras de literatura, de pesquisa e de referência'. Para as crianças dos anos iniciais, há obras com textos em prosa, sobretudo os contos, em verso (poemas, cantigas, parlendas, advinhas), livros de imagens e livros de histórias em quadrinhos. Esses 
livros são destinados às bibliotecas das escolas" (BRASIL, 2012a).

${ }^{3} \mathrm{O}$ sentido aqui se refere ao uso da literatura como forma utilitária e pragmática ou como uso de ensino moralizante (PERROTTI, 1986; CADEMARTORI, 1994; ZILBERMAN; MAGALHÃES, 1987).

${ }^{4}$ Consta no documento intitulado Acervos complementares: alfabetização e letramento nas diferentes áreas do conhecimento (BRASIL, 2012a), que o objetivo é "apoiar os professores, trazendo sugestôes gerais para a utilização dos acervos em sala de aula de aula. $\mathrm{O}$ acesso aos acervos complementares, além de subsidiar o trabalho docente, contribuirá para a familiarização das crianças em processo de alfabetização com a cultura da escrita. As obras selecionadas, além de diversificadas do ponto de vista temático, dos gêneros e formato, também diferem do ponto de vista do grau de complexidade. Portanto, os acervos são compostos por obras que estimulam a leitura autônoma por parte do alfabetizando ou propiciam a professores e alunos alternativas interessantes de leitura compartilhada".

${ }^{5}$ Livros literários narrativos (334); Histórias em quadrinhos (22); Biografias (25); Livros de histórias, com foco em conteúdos curriculares(461); Livros de divulgação do saber científico, obras didáticas (184); Livros instrucionais (13); Livros de imagens (sem legenda) (43); Livros de palavras, livros de imagens com legenda, livros com textos rimados de apresentação das letras do alfabeto (47); Livros de cantigas, parlendas, trava-línguas, jogo de palavras, poemas (110); Outros (obras mistas, com vários gêneros, materiais de atividades didáticas encadernadas, obras pedagógicas) (105) (BRASIL, 2012a).

${ }^{6}$ Cf. Projeto Ciranda dos Livros (1980 a 1989); Programa Nacional de Salas de Leitura (PNSL) (1989-1996); Programa Nacional Biblioteca da Escola (PNBE) (1997-2014).

7 “Os cadernos de alfabetização em Língua Portuguesa foram organizados para favorecer o desenvolvimento do trabalho de formação continuada do professor alfabetizador e contêm sugestóes de atividades para que o professor reflita sua ação e articule com estudos teóricos" (SOUZA, 2014). Sobre os cadernos ver também Pacto Nacional Pela Alfabetização na Idade Certa: formação de professores ao Pacto Nacional pela Alfabetização na Idade Certa (BRASIL, 2012b). 


\section{REFERÊNCIAS}

BAZZO, Jilvania Lima dos Santos; CHAGAS, Lilane Maria de Moura. Leitura de fruição no Programa Nacional de Alfabetização na Idade Certa no estado de Santa Catarina. Revista Linha Mestra, Campinas, SP, ano 8, n. 24, p. $1640-1658$, jan./jul. 2014).

BISSOLI, Michelle de Freitas; CHAGAS, Lilane Maria de Moura. Infância e Leitura: formação da criança leitora e produtora de texto. Manaus: Valer, 2012.

BRASIL. Ministério da Educação. Conselho Nacional de Educação. Câmara de Educação Básica. Resolução n ${ }^{\circ}$, de 14 de dezembro de 2010. Fixa Diretrizes Curriculares Nacionais para oEnsino Fundamental de 9 (nove) anos. Diário Oficial da União, Brasília, DF, 15 dez 2010.

BRASIL. Ministério da Educação. Secretaria de Educação Básica. Acervos complementares: alfabetização e letramento nas diferentes áreas do conhecimento. Brasília: MEC/SEB, 2012a.

BRASIL. Ministério da Educação. Secretaria de Educação Básica. Pacto Nacional pela Alfabetização Na Idade Certa: formação de professores no pacto nacional pela alfabetização na idade certa. Brasília: MEC/SEB, 2012b.

BRASIL. Ministério da Educação. Secretaria de Educação Básica. Pacto Nacional pela Alfabetização Na Idade Certa: formação do professor alfabetizador : caderno de apresentação / Ministério da Educação. Brasília: MEC/SEB, 2012c.

CADEMARTORI, Lígia. O que é literatura infantil. São Paulo: Brasiliense, 1994.

COSSON, Rildo. Letramento Literário: teoria e prática. São Paulo: Contexto, 2009.

FOUCAMBERT, Jean. A criança, o professor e a leitura. Porto Alegre: Artes Médicas, 1997.

MACHADO, Regina. Acordais: fundamentos teórico-poéticos da arte de contar histórias. São Paulo: DCL, 2004. 
MANGUEL, Alberto. Uma história da leitura. São Paulo: Companhia das Letras, 1997.

PALEY, Vivian. Buscando a la Urraca: otra voz en el aula. In: MCEWAN, Hunter; EGAN, Kieran (Org.). La narrativa en la enseñanza, el aprendizaje y la investigación. Buenos Aires: Amorrortu, 1998. (Colección Agenda educativa). p. 139-149.

PERROTI, Edmir. O texto sedutor na literatura infantil. São Paulo: Ícone, 1986. (Coleção Educação Crítica).

SMITH, Frank. Leitura Significativa. Porto Alegre: Artes Médicas, 1999.

SOUZA, Elaine Eliane Peres de. A formação continuada do Professor Alfabetizador nos Cadernos do Pacto Nacional pela Alfabetização na Idade Certa (PNAIC). 2014. 358p. Dissertação (Mestrado em Educação) Universidade Federal de Santa Catarina. Florianópolis, 2014.

ZILBERMAN, Regina; MAGALHAES, Ligia Cademartori. Literatura Infantil: autoritarismo e emancipação. São Paulo: Ática. 1987. 


\section{La literatura infantil en la alfabetización: la formación de los niños lectores}

\section{Resume}

El presente texto aborda algunas formas de pensar la literatura infantil en los primeros ańos de la educación primaria. Interesa presentar, en este texto, algunas formas posibles de aproximación a la literatura en este nivel de la enseñanza. Creemos que al integrar activamente la literatura infantil en el proceso de alfabetización (conocimiento de la oralidad y de la escrita, de las diversas formas verbales $y$ no verbales de comprender y descubrir el mundo) y en la adquisición y ampliación del lenguaje, estaremos contribuyendo para la formación literaria de los niños y niñas. Así, en un primer momento, y sin agotar el tema, desarrollamos algunas cuestiones teóricas en relación al tema: literatura infantil, lectura y los nińos. En un segundo momento, realizamos algunas reflexiones sobre las prácticas de lectura que los niños y niñas del ciclo de alfabetización (primeros años de la educación primaria) están vivenciando a partir del contacto con el Acervo Complementar do Programa Nacional do Libro Didáctico (PNLD) e con el Programa Nacional de Bibliotecas Escolares (PNBE) que están incluidos en el material distribuida por el Programa Nacional de Alfabetización en la Edad Cierta (PNAIC) en Brasil. Resaltamos una antigua y permanente preocupación cuando se trata de la relación de la

\section{Children's literature in literacy: the formation of the child reader}

\section{Abstract}

The present text discusses some ways of thinking children's literature during the fundamental education literacy cycle. It also aims to introduce some forms to approach literature at this educational level. We believe that by integrating children's literature in both the literacy process (knowledge of orality and writing, of the several verbal and non-verbal forms of understanding and discovering the world) and the acquisition and expansion of language, we are contributing for the children's literary formation. So, firstly, but not exhaustively, we will develop here some theoretical questions regarding children's literature, reading and childhood. Our second aim is to reflect on reading practices the children are experiencing in the literacy cycle from their contact with the Complementary Collection of the Didactic Book National Program (Acervo Complementar do Programa Nacional do Livro Didático - PNLD) and the School Library National Program (Programa Nacional de Bibliotecas Escolares - PNBE), included in the handouts distributed by the National Pact for Literacy at the Correct Age (Programa Nacional de Alfabetização na Idade Certa - PNAIC) in Brazil. We emphasize here an old and permanent concern regarding literature and education when it approaches on how the 
literatura y educación en relación como ha sido trabajada la literatura producida para los niños. ¿De esta forma, que implicaciones tiene la literatura dentro de los programas de formación de docentes? Finalizamos el texto otorgando destaque para los programas de incentivo a la lectura como una contribución significativa para la formación de los niños lectores

Palabras claves: Literatura infantil. Formación del lector. Ciclo de Alfabetización. literature produced for children has been handled. What are the implications that literature has on the teacher's tranining programs? We conclude by highlighting the programs that motivate children to read as a significant contribution to form the child reader.

Keywords: Children Literature. Reader training. Literacy cycle.

\section{Lilane Maria de Moura Chagas E-mail: lilanemoura@gmail.com}

\section{Chirley Domingues}

E-mail: chirleydomingues@yahoo.com

Enviado em: 7/8/2014 Aprovado em: 5/12/2014 